\title{
Environmental Controls Over Actinobacteria Communities in Ecological Sensitive Yanshan Mountains Zone
}

\author{
Hui Tang ${ }^{1,2,3}$, Xunxun Shi ${ }^{1,2,3}$, Xiaofei Wang ${ }^{1,2,3}$, Huanhuan Hao ${ }^{1,2,3}$, Xiu-Min Zhang ${ }^{1,2,3}$ \\ and Li-Ping Zhang 1, 2,3* \\ ${ }^{1}$ College of Life Sciences, Hebei University, Baoding, China, ${ }^{2}$ The Key Lab of Microbial Diversity Research and Application of \\ Hebei Province, Baoding, China, ${ }^{3}$ Key Laboratory of Medicinal Chemistry and Molecular Diagnosis, Ministry of Education, \\ Hebei University, Baoding, China
}

\section{OPEN ACCESS}

Edited by:

Syed Gulam Dastager,

NCIM Resource Center, India

Reviewed by:

Polpass Arul Jose,

Madurai Kamaraj University, India

Xi-Ying Zhang,

Shandong University, China

*Correspondence:

Li-Ping Zhang

zhlping201@163.com;

zhlping@hbu.edu.cn

Specialty section:

This article was submitted to

Extreme Microbiology,

a section of the journal

Frontiers in Microbiology

Received: 22 September 2015

Accepted: 03 March 2016

Published: 22 March 2016

Citation:

Tang $H$, Shi $X$, Wang $X$, Hao $H$,

Zhang $X-M$ and Zhang L-P (2016)

Environmental Controls Over

Actinobacteria Communities in

Ecological Sensitive Yanshan Mountains Zone.

Front. Microbiol. 7:343.

doi: 10.3389/fmicb.2016.00343
The Yanshan Mountains are one of the oldest mountain ranges in the world. They are located in an ecologically sensitive zone in northern China near the Hu Huanyong Line. In this metagenomic study, we investigated the diversity of Actinobacteria in soils at 10 sites (YS1-YS10) on the Yanshan Mountains. First, we assessed the effect of different soil prtreatment on Actinobacteria recovery. With the soil pretreatment method: air drying of the soil sample, followed by exposure to $120^{\circ} \mathrm{C}$ for $1 \mathrm{~h}$, we observed the higher Actinobacteria diversity in a relatively small number of clone libraries. No significant differences were observed in the Actinobacterial diversity of soils from sites YS2, YS3, YS4, YS6, YS8, YS9, or YS10 $(P>0.1)$. However, there were differences $(P<0.05)$ from the YS7 site and other sites, especially in response to environmental change. And we observed highly significant differences $(P<0.001)$ in Actinobacterial diversity of the soil from YS7 and that from YS4 and YS8 sites.. The climatic characteristics of mean active accumulated temperature, annual mean precipitation, and annual mean temperature, and biogeochemical data of total phosphorus contributed to the diversity of Actinobacterial communities in soils at YS1, YS3, YS4, and YS5 sites. Compared to the climatic factors, the biogeochemical factors mostly contributed in shaping the Actinobacterial community. This work provides evidence that the diversity of Actinobacterial communities in soils from the Yashan Mountains show regional biogeographic patterns and that community membership change along the north-south distribution of the Hu Huanyong Line.

Keywords: ecological sensitive zone, a Yanshan mountains, Actinobacteria, phylogenetic diversity, 16S rRNA Actinobacterial clone library

\section{INTRODUCTION}

Microbial communities can diverge rapidly, and result in distinct biogeographic patterns (Green et al., 2008). However, based on different evolution, biogeographic patterns are posited to consist of dramatic range expansion as a result of effect at the genotype level (Ramette and Tiedje, 2007). For microbial biogeography, the traditional view has been that "Everything is everywhere, 
but the environment selects" (Baas, 1934). There has been a debate over whether variation in microbial communities through space results from environmental, or from geographic barriers and other human activities that contribute to community structure (Eisenlord et al., 2012). If not all microbes are evenly dispersed over time, this would suggest that forces structuring the microbial communities are more complex than only adaptive evolution via natural selection (Bissett et al., 2010; Kuang et al., 2015; Yang et al., 2015). We addressed this issue by examining the community structure of a deeply diverse and divergent phylum, the Actinobacteria. Actinobacteria are important organisms that mediate plant litter decay and the subsequent formation of soil organic matter in terrestrial ecosystems. This phylum is phylogenetically divergent and the closest prokaryotic relative is yet to be identified (Ventura et al., 2007; Mendes et al., 2015). Actinobacteria express a variety of morphologies and life-history traits that could be advantageous for dispersal, including sporulation. Here, we evaluated by metagenomic technology whether environmental disturbance of an ecologically sensitive zone is associated with a highly structured community of soil Actinobacteria in the Yanshan Mountains of northern China. Microorganisms are the most diverse and abundant group of organisms on Earth; however, in soil microbial communities, work to understand this diversity has been primarily directed toward general rather than group-specific diversity. Actinobacteria, ubiquitously found in terrestrial (Han et al., 2015), freshwater (Mullowney et al., 2015), and marine (Sun et al., 2015) ecosystems, are the dominant soil bacterial phylum and they are believed to play multiple roles in the environment (Barka et al., 2016).

The construction of metagenomic libraries and other DNAbased metagenomic projects are initiated by the isolation of highquality DNA that is suitable for cloning and that covers the microbial diversity present in the original sample. Since Pace et al. (1985) first proposed the direct cloning of environmental DNA, soil DNA extraction techniques, including both direct and indirect methods (Robe et al., 2003; Delmont et al., 2010), have been developed. These efforts have led to the development of various homemade DNA extraction protocols, as well as commercial kits, which have been used in more than 1000 studies reported yearly. Therefore, high quality DNA has been isolated from a variety of environments. In addition, cultivationindependent methodologies, particularly sequence analyses of cloned 16S ribosomal RNA genes (16S rDNA) are powerful tools to investigate microbial diversity. Most approaches target the 16S rRNA gene for PCR amplification and subsequent Sanger sequencing of the clone libraries (Sogin et al., 2006), ribosomal sequence tags (SARST; Poitelon et al., 2009), denaturing gradient gel electrophoresis (DGGE; Yim et al., 2015), terminal restriction fragment length polymorphism (T-RFLP; Lazzaro et al., 2015), Pyrosequencing (Schäfer et al., 2010), or 454 Life Sciences and Illumina analyses (Vasileiadis et al., 2012; Logares et al., 2014). However, there is no specific primers for Actinobacteria to construct a full or near full-length $16 \mathrm{~S}$ rDNA clone libraries. And the Actinobacterial-specific primers used for high-throughput technique can obtain some information of Actinobateria, but sometimes the recovered sequence is too small to gain complete genetic information and detailed phylogenetic characterization of Actinobacteria, especially for a greater number of unclassified Actinobacteria.

Therefore, in this study, it was purpose to obtain a full or near full-length 16S rDNA sequence of Actinobacteria. To increase the proportion of Actinobacteria in the 16S rDNA library, we developed a method of soil pretreatment to concentrate the Actinobacterial community, and used a PCR primer system to capture Actinobacteria from prokaryotes in the 16Sr DNA fulllength clone library. The purpose of the present study was to compare the community structure and phylogenetic diversity of Actinobacteria among various sites in the Yanshan Mountains.

\section{METHODS}

\section{Sample Collection}

Soil samples were collected from various locations in the Yanshan Mountains (Figure 1) on October 2-10, 2011. Descriptions of soil collection sites are presented in Table 1 . In each of the 10 sites, there were 3 randomly selected $30 \mathrm{~m} \times 30 \mathrm{~m}$ replicate plots 100-150 m apart. In each plot, we collected 10 soil samples using a $2.5 \mathrm{~cm}$ diameter soil core, which extended to a depth of $10 \mathrm{~cm}$. The 10 soil samples in each plot were composited and passed through a $2-\mathrm{mm}$ sieve in the field. By pooling the 10 soil cores, we aggregated spatial heterogeneity at the scale of individual plots. The 3 soil plot samples were combined into a representative sample for each site. From the sieved composite sample, a 5.0g sample was removed for DNA extraction. This was done to allow a characterization of the Actinobacteria community at the scale of the entire Yanshan Mountains, and to explore regional trends in community similarity that may have been structured by environmental factors.

\section{DNA Extraction Methods}

We design three kinds of soil pretreatment method to improve the proportion of Actinobacteria DNA. (i) For protocol A, air dried soil sample were treated by $120^{\circ} \mathrm{C} 1 \mathrm{~h}$ (A1), $2 \mathrm{~h}$ (A2), $3 \mathrm{~h}$ (A3) respectively; (ii) For protocol $\mathrm{B}$, soil sample were treated by air drying processing 15 days (B1), 30 days (B2), 45 days (B3) respectively; (iii) For protocol C, soil sample were treated by $0.1 \%$ Polymyxin B Sulfate immersion $1 \mathrm{~h}$ (C1), $2 \mathrm{~h}$ (C2), $3 \mathrm{~h}$ (C3) respectively; After pretreatment of soil samples, and centrifugal washing three times with sterile water for removing DNA of release, DNA extraction from $1.0 \mathrm{~g}$ soil samples was carried out using the PowerSoil ${ }^{\mathrm{TM}}$ DNA Isolation Kit (Mo Bio Laboratories), according to the manufacturer's instructions. The yield and integrity of the environmental DNA obtained were confirmed through electrophoresis in 1\% agarose gel.

\section{Construction of 16S rRNA Gene Libraries}

The purified DNA was used as a template to specifically amplify $16 \mathrm{~S}$ rRNA gene fragments, a $\sim 1500$ bp region using the bacteria-specific primers (Lane, 1991): $27 \mathrm{~F}$ (5-AGAGTTTGATCC/ATGGCTCAG-3) and 1525R (5AAGGAGGTGA/TTCCAA/GCC-3). To recondition the PCR product for elimination of heteroduplexes in mixed-template PCR (Janelle et al., 2002), the amplified reaction was diluted 



FIGURE 1 | Various sampling points along ecological sensitive Yanshan mountains zone. The circular mark denotes the stations. The photograph and topographic map were provided by the Mapword (http://map.tianditu.com/map/index.html. Red line is Hu Huanyong Line). 
TABLE 1 | Actinobacteria sequencing statistics and $\alpha$ diversity measures of different pretreatment of soil samples.

\begin{tabular}{|c|c|c|c|c|c|c|}
\hline Source $^{a}$ & Total no. of clones & Detection rate $(\%)$ & OTU & Shannon diversity index (H/ (loge)) & Equitability_J & Buzas and Gibson's evenness (E) index \\
\hline $\mathrm{A} 1$ & 102 & 20.4 & 74 & 4.161 & 0.9668 & 0.866 \\
\hline $\mathrm{A} 2$ & 30 & 6.0 & 19 & 2.731 & 0.9674 & 0.807 \\
\hline A3 & 73 & 14.6 & 64 & 4.101 & 0.9762 & 0.943 \\
\hline B1 & 44 & 8.8 & 38 & 3.595 & 0.9783 & 0.958 \\
\hline B2 & 28 & 5.6 & 26 & 3.233 & 0.9724 & 0.975 \\
\hline B3 & 84 & 15.8 & 61 & 4.020 & 0.9779 & 0.913 \\
\hline C1 & 55 & 11.0 & 37 & 3.464 & 0.9693 & 0.863 \\
\hline C2 & 29 & 5.8 & 23 & 3.062 & 0.9767 & 0.929 \\
\hline C3 & 24 & 4.8 & 20 & 2.925 & 0.9765 & 0.931 \\
\hline CK & 18 & 3.6 & 15 & 2.659 & 0.9720 & 0.952 \\
\hline
\end{tabular}

a Sources of data are from the following libraries: uncultured Actinobacteria are from treated samples $A 1, A 2, A 3, B 1, B 2, B 3, C 1, C 2, C 3$, and $C K$.

${ }^{b}$ OUT were defined as clone sequences with $<97 \% 16$ S rRNA gene sequence similarity to other clones.

10 -fold into a fresh reaction mixture of the same composition and cycled three times. The size and quality of the resulting PCR products was confirmed by agarose gel electrophoresis ( $1.4 \%$ agarose). They were then cloned into the pUCm-T linear plasmid vector (Takara Bio Group, Code D101A) and then into E. coli DH5a competent cells (Takara Bio Group). After the transformants were grown overnight, single-clone colonies were picked up with sterile toothpicks and transferred into $1.5 \mathrm{~mL}$ microcentrifuge tubes containing $50 \mathrm{~mL}$ of TE buffer. The tubes were heated for $15 \mathrm{~min}$ at $95 \mathrm{C}$ to lyse the cells, and then chilled on ice. Insert $16 \mathrm{~S}$ rDNA sequences were identified by M13/pUC sequencing primer and M13/pUC reverse primer (approximately $1.5 \mathrm{~kb})$.

\section{Amplification and Sequencing of Actinobacteria 16S rRNA Genes}

Two different Actinobacteria-specific primer sets specifically targeting 16S rRNA gene were used to confirm the presence of selected Actinobacteria genotypes in soil DNA. The first primer set, Com2xf /Ac1186 (Schäfer et al., 2010), was used to detect most Actinobacteria species. The $25-\mu \mathrm{L}$ PCR reaction mixture contained $2.5 \mu \mathrm{L}$ PCR buffer, $2 \mu \mathrm{L} \mathrm{MgCl} 2(25 \mathrm{mM}), 2 \mu \mathrm{L}$ dNTPs $(2.5 \mathrm{mM}), 0.5 \mu \mathrm{L}$ each primer $(10 \mu \mathrm{M}$, Shenggong Biotech, Shanghai, China), $17.7 \mu \mathrm{L} \mathrm{H}_{2} \mathrm{O}, 0.2 \mu \mathrm{L}$ BSA $\left(20 \mathrm{mg} / \mathrm{mL}^{-1}\right)$, and $0.1 \mu \mathrm{L}$ Taq polymerase $\left(5 \mathrm{U} / \mu \mathrm{L}^{-1}\right)$ (Takara, Japan). This mixture was added directly to cloned cells. PCR was carried out in a thermocycler (Bio-Rad, München, Germany) with an initial denaturation step at $95^{\circ} \mathrm{C}$ for $10 \mathrm{~min}$, followed by 25 cycles of $30 \mathrm{~s}$ at $94^{\circ} \mathrm{C}, 30 \mathrm{~s}$ at $60^{\circ} \mathrm{C}$, and $30 \mathrm{~s}$ at $72^{\circ} \mathrm{C}$, followed by a final extension at $72^{\circ} \mathrm{C}$ for $5 \mathrm{~min}$. A second PCR using the primer set SC-Act235-aS-20/SC-Act878-aA-19 (Stach et al., 2003) was carried out to increase the amount of detectable Actinobacteria DNA. The $25-\mu \mathrm{L}$ reaction mixture contained $2.5 \mu \mathrm{L}$ PCR buffer, $2.5 \mu \mathrm{L} \mathrm{MgCl}_{2}$ (25 mM), $2 \mu \mathrm{L}$ dNTPs $(2.5 \mathrm{mM}), 0.5 \mu \mathrm{L}$ each primer $(10 \mu \mathrm{M}$, Shenggong Biotech, Shanghai, China), $17.7 \mu \mathrm{L}$ $\mathrm{H}_{2} \mathrm{O}, 0.2 \mu \mathrm{L}$ BSA $\left(20 \mathrm{mg} / \mathrm{mL}^{-1}\right)$, and $0.1 \mu \mathrm{L}$ Taq polymerase $(5$ $\left.\mathrm{U} / \mu \mathrm{L}^{-1}\right)$ (Takara, Japan). The reaction mixture was also added directly to cloned cells. PCR was performed with an initial denaturation step at $95^{\circ} \mathrm{C}$ for $10 \mathrm{~min}$, followed by 25 cycles of $30 \mathrm{~s}$ at $94^{\circ} \mathrm{C}, 30 \mathrm{~s}$ at $60^{\circ} \mathrm{C}$, and $1 \mathrm{~min}$ at $72^{\circ} \mathrm{C}$, followed by a final extension at $72^{\circ} \mathrm{C}$ for $5 \mathrm{~min}$. The success of PCR reactions were determined by subjecting the amplified products to $1 \%$ agarose gel electrophoresis and ethidium bromide staining. All positive clones and the A3 clone library were recultured in LB broth, and sequenced using Shenggong Biotech, Shanghai, China.

\section{Phylogenetic Analyses}

The 16S rRNA gene sequences were taxonomically assigned using the Naïve Bayesian rRNA classifier of the Ribosomal Database Project II (RDP; Wang et al., 2007). Sequences from this study were subsequently aligned using the ClustalW multiple alignment tool from BioEdit v7.0.5.3. The program DNADIST $\mathrm{v} 3.5 \mathrm{c}$ in BioEdit was used to compute a distance matrix from the aligned nucleotide sequences. The distance matrix was input into the DOTUR program (v1.53) to assign the sequences to operational taxonomic units (OTUs) using the furthest-neighbor clustering algorithm (Schloss and Handelsman, 2005) at 97, 95, and $90 \%$ identities. Sequences from each clone library were aligned separately, and OTUs were identified at $97 \%$ identity. One representative sequence was selected for each OTU. Representative sequences from each OTU (97\%) in 10 libraries determined in this study were deposited in the NCBI database under accessions no. KC554071-KC554721. Coverage (C) was used as a measure of captured diversity, where C is expressed by $1 \_n 1 / \mathrm{N}$, in which $\mathrm{n} 1 / \mathrm{N}$ is the ratio of the number clones that appeared only once (n1) to the total number of clones $(\mathrm{N})$. Rarefaction curves were produced by standard calculations by comparing the total number of clones obtained to the number of clones representing unique OTUs. Sampling sufficiency of each library was determined as described by Kemp and Kemp and Aller (2004) using the "Large Enough" estimator available online at http://www.aslo.org/lomethods/ free/2004/0114a.html. The Shannon index, Simpson's diversity index, and nonparametric richness estimators ACE and Chaol were calculated using the DOTUR program (Schloss and Handelsman, 2005). A neighbor-joining tree was created using MEGA version 4 software. The bootstrap values represent 1000 samplings. Multiple environments were simultaneously analyzed using phylogenetically comparing the microbial communities using weighted and unweighted UniFrac to conduct a principal 
coordinates analysis (Lozupone et al., 2006). The neighborjoining tree generated for input to UniFrac was limited to 999 sequences. The environmental input file for UniFrac contained a count of how many times the selected sequence appeared in the clone library. The UniFrac significance test with abundance weights was used to determine significant differences in the Actinobacteria community structure. $P$-values were corrected for multiple comparisons by multiplying the calculated $P$-value with the number of comparisons made (Bonferroni correction; Lozupone et al., 2006).

\section{Environmental Variables and Multivariate Statistical Analysis}

Environmental characteristics were assembled into two data sets: (1) a biogeochemical data set composed of factors, and (2) climatic characteristics. The biogeochemical data matrix included soil $\mathrm{pH}$ and total nitrogen $(\mathrm{TN})$; total phosphorus (TP); available phosphorus (AP); available potassium (AK); organic matters (OM) (Supplementary Table 1). The second matrix characterized climatic variation by including annual mean temperature (MT); annual mean precipitation (MP); mean sea level elevation (ME); annual mean sunshine duration (SD); mean active accumulated temperature $\left(>10^{\circ} \mathrm{C}\right.$ ) (AAC) (Supplementary Table 2). The climatic data used in this study were averages from the years 1981 to 2012. Environmental vectors, of biogeochemical and climatic data sets, were fit to nMDS ordinations of biological data, which identified the individual variables correlated with community patterns. Redundancy analysis (RDA) was used to examine the correlations between species patterns and environmental variables to evaluate which variables explained significant proportions of variation in Actinobacteria community composition. Additional statistics were conducted in the R package vegan (Oksanen et al., 2011).

\section{RESULT}

\section{Testing of an Actinobacteria Primer System}

The Actinobacteria specific primer systems detected 75 positive clones from the 16S rDNA clone library of the A3 sample. To determine the validity and specificity of the primer system, all clones in the library were sequenced and classified. Two out of 75 positive clones and another 425 clones belonged to the Acidobacteria, Proteobacteria and Firmicutes, and 73 positive clones were Actinobacteria belonging to 20 known and 34 unknown genera.

\section{Effect of Different Soil Pretreatments on Actinobacteria Recovery}

After soils were pretreated, we detected a larger number and phylotype $s$ of Actinobacteria in the same numbers of prokaryotic microorganisms in the $16 \mathrm{~S}$ rDNA cloned library (Table 1). It were corroborated by the diversity indices, which were significantly higher than direct extraction of Kit (CK). In addition, the number Actinobacteria clones detected was significantly different among samples treated by the 3 pretreatment methods. The total detection rate using each of these methods were: A (13.7\%) > B (10.4\%) > C (7.2\%). Protocol
A1 yielded 102 clones with a 20.4\% detection rate (from 500 clones); protocol B3 yielded 84 with $15.8 \%$ detection; protocol A3 yielded 73 with $14.6 \%$ detection; CK yield 18 with $3.6 \%$ detection. Sequences with $97 \%$ similarity in the $16 \mathrm{~S}$ rRNA gene used for phylogenetic analyses were combined into OTUs. A total of 252 OTUs were present in the 10 clone libraries. Most of them were A1 (74 out of 102 clones), next were A3 (64 out of 73 clones), third were B3 (62 out of 84 clones), while CK had only 15 (out of 18 clones). In addition, only A1 contained all OTUs recovered by CK. Even if the rarefaction curves did not approach an asymptote (Figure 2), meaning that we did not capture the full diversity of the Actinobacterial community, 10 clones representing 37 known genera out of a total of 186 genera were detected, with A1 yielding 21 (out of 56) known genera; A3 yielding 20 (out of 54) genera; B3 yielding 17 (out of 54) genera. They were all far more than CK, 8 out of 12 genus. Nocardioids and Conexibacter and some unclassified groups were detected in the 10-clone library. Unique known genera detected using the A1 method were Dactylosporangium, Lechevalieria, and Amycolatopsis; A3 resulted in the detection of Kineosporia and Angustibacter; B2, Microlunatus and Actinoplanes; B3, Geodermatophilus and Kribbella; C1, Acidothermus and Phycicoccus; and C2, Nesterenkonia and Aeromicrobium. The A2, B1, and C3 had not unique known genus but unclassified group (Figure 3). The Actinobacterial compositions at the order/suborder levels were significantly different between the pretreated or untreated soil samples (Figure 4). The pretreated soil allowed increased detection of specific orders/suborders, including Solirubrobacterales, Propionibacterineae, Frankineae, Acidimicrobiales, and Micrococcineae. However, Corynebacterineae, Kineosporiineae, and Rubrobacterales were only detected in the A3 library, which clearly indicated that pretreatment of soil could lead to an underestimation of some Actinobacteria groups. Furthermore, the Actinobacterial library was dominated by the Solibubrobacterales (A2, 6.8\%; C1, 38.2\%) of the Actinobacteria clones and A2, $0.4 \% ; \mathrm{B} 3,-6.4 \%$ of all $16 \mathrm{~S}$ rDNA clones, whereas Propionibacterineae dominated the A1 and A2 libraries (24.0\% of the Actinobacterial clones and $24.1 \%$ of all $16 \mathrm{~S}$ rDNA

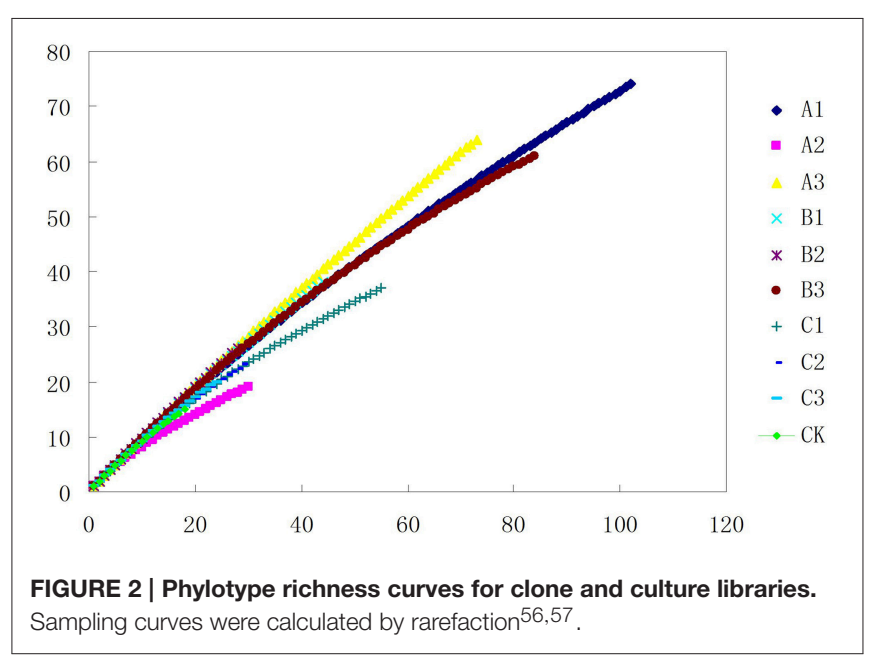




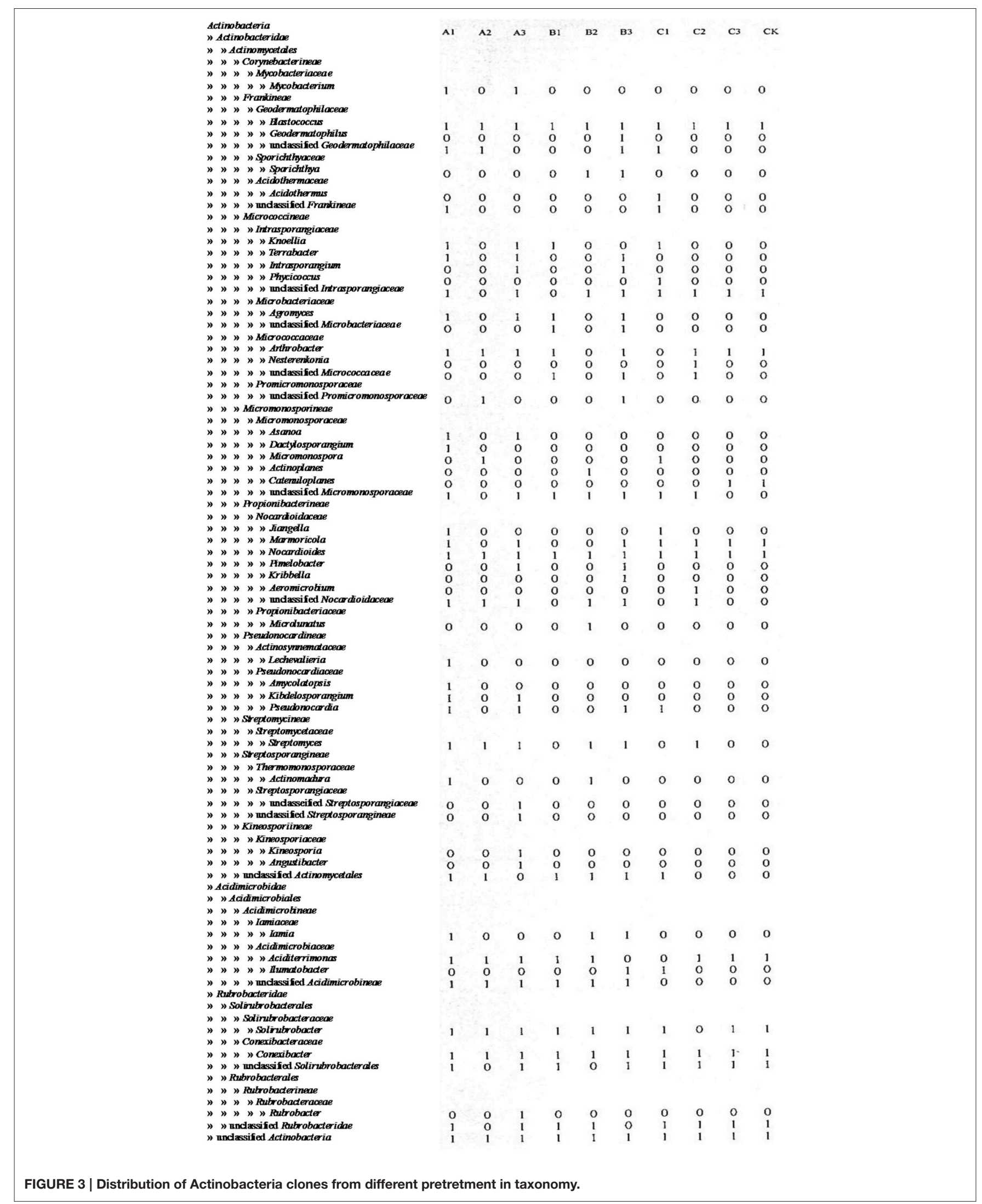




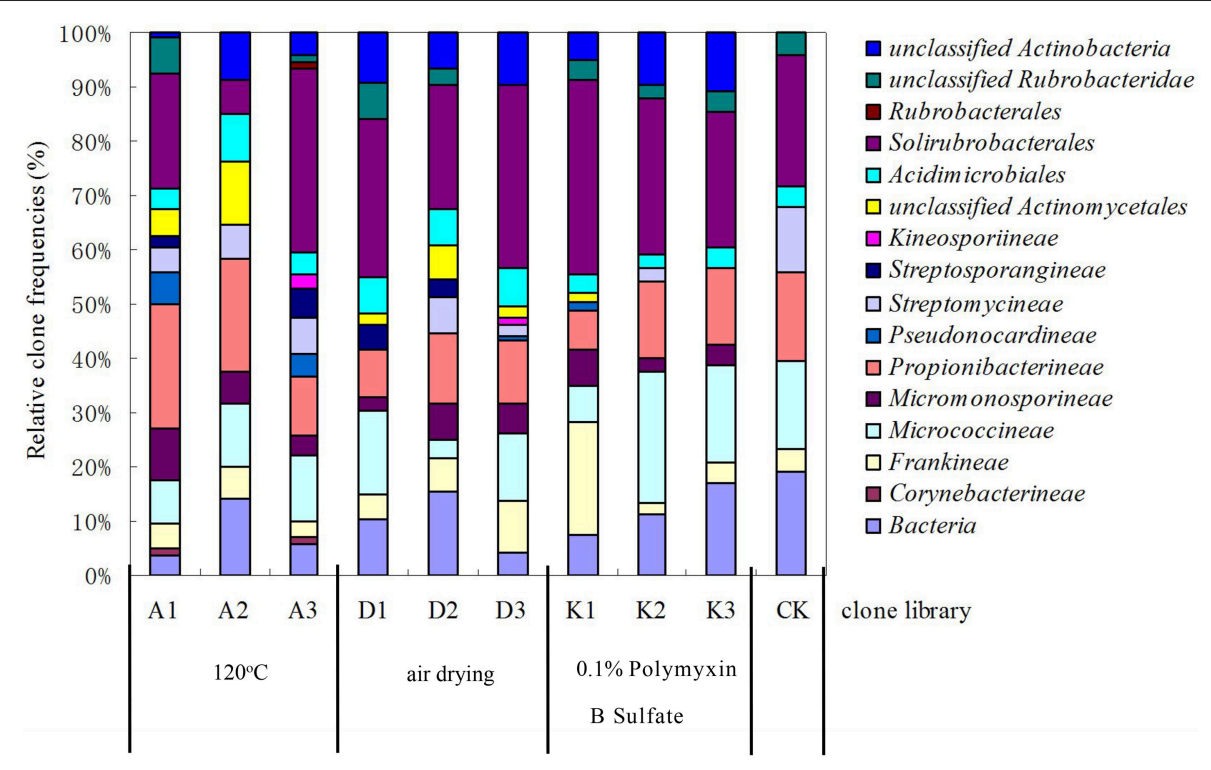

FIGURE 4 | Relative clone frequencies in major phylogenetic groups of the clone libraries from different pretreatment of soil sample.

clones; Figure 4). The B3 library allowed the detection of a greater number of unclassified Actinobacteria, unclassified Rubrobacteridae, and unclassified Actinomycetales than the A1 library.

\section{Actinobacteria Community Composition at Stations in the Yanshan Mountains}

Soil samples from 10 stations were treated at $120^{\circ} \mathrm{C}$ for $1 \mathrm{~h}$, then the bacterial 16S rDNA clone library was constructed. We randomly selected 1000 clones (for sufficient Actinobacterial coverage) from each station to detect Actinobacteria using 2 Actinobacteria-specific primer sets. From the 10,000 clones generated, approximately $13 \%(n=1327)$ resulted in PCR products from the Actinobacteria-specific primers.

Depending on the station surveyed, the proportion of Actinobacteria among total clones varied between 10.8 and $20.4 \%$ (Table 2), and resulted in 575 OTUs grouped at the $97 \%$ similarity level. The "Large Enough" calculator was used to determine whether individual clone libraries were sampled sufficiently. If the estimated phylotype richness reached an asymptote, we inferred that the library was large enough to yield a stable estimate of phylotype richness. According to the figure, all sites appeared to have been sufficiently sampled (Supplementary Figure 1). We identified OTUs in 28 of 39 Actinobacterial families, classified by the RDP (Figure 5). For the most abundant OTUs, the closest similarity to known organisms was $100 \%$ to members of the Blastococcus genus, Frankineae family. UniFrac metrics were used to assess community similarity between 2 or more samples according to their structure (weighted/quantitative) and membership (unweighted/quantitative). In the 2-dimensional plot visualized by the UniFrac weighted distance matrix principle coordinates analysis ( $3 \%$ dissimilarity), the samples of each system distinctively responded to the majority of the variation detected in the samples across 2 axes (Figure 7A). Axis 1 accounted for $21.82 \%$ of the variation, and Axis 2 accounted for $19.29 \%$ of the variation. In Figure $7 \mathbf{B}$, the same 2-dimensional plot was shown for the unweighted method, which showed that samples from the same type, were in consideration of community membership, although less distinctive (Axis $1=16.72 \%$, Axis $2=$ 13.14\%). The results from the UniFrac weighted and unweighted PCA plots demonstrate distinctions in structure and composition of the Actinobacterial communities from different stations. Furthermore, the UniFrac significance test results revealed significant differences in community membership between sites YS1 and YS6 $(P<0.001)$, sites YS4 and YS7 $(P<0.001)$, and sites YS7 and YS8 $(P<0.001)$ (Supplementary Figure 2$)$. Diversity estimates, Ace and Chao1, indicated that YS6, YS7, and YS9 were more diverse than the other sites.

Conexibacteraceae, Geodermatophilaceae, Micrococcaceae, Micromonosporaceae, Nocardioidaceae, Propionibacteriaceae, Pseudonocardiaceae, and Solirubrobacteraceae represented 46.4$66.9 \%$ of the bacterial community in each station. These taxa together accounted for an average of $55 \%$ of the Actinobacterial clones obtained from soil of the 10 stations in the Yanshan Mountains. Geodermatophilaceae, Micromonosporaceae, Nocardioidaceae, Propionibacteriaceae, Pseudonocardiaceae, Streptomycetaceae, and Solirubrobacteraceae were common to the 10 libraries, and they were identified as contributing substantially to the relative abundance of Actinobacteria (Figure 5). To demonstrate the differences in Actinobacterial community composition, relative abundances of Actinobacteria were also assessed. Table 3 displays the relative abundances and Shannon diversity indices of the salient families of Actinobacteria identified in the soils from the 10 stations. Groups of family, YS10 were fewest, YS4 were most. The UniFrac 
metric identified the unique phylogenetic branch belonging to Actinobacterial communities within each site compared to the entire community $(P=0.001)$. The unique family of site YS3 was Cryptosporangiaceae, YS4 was Rarobacteraceae, and YS6 was Jiangellaceae, and the unique families of YS7 were Acidothermaceae and Cellulomonadaceae.

Non-metric multi-dimensional Scaling of a Bray-Curtis distance matrix demonstrated that some soil properties and/or spatial factors resulted in greater divergence within the Actinobacteria population (Figure 8). Axes 1 and 2

TABLE 2 | Actinobacteria sequencing statistics and $\alpha$ diversity measures of soil samples of Yanshan mountains zone.

\begin{tabular}{lcccccc}
\hline Source $^{\mathbf{a}}$ & $\begin{array}{c}\text { Total no. } \\
\text { of clones }\end{array}$ & OTU $^{\mathbf{b}}$ & $\begin{array}{c}\text { Shannon } \\
\text { diversity } \\
\text { index (H/) }\end{array}$ & $\begin{array}{c}\text { Pielou's } \\
\text { evenness } \\
\text { (J') index }\end{array}$ & Chao 1 & ACE \\
\hline YS1 & 114 & 76 & 4.127 & 0.9529 & 198.04 & 255.21 \\
YS2 & 125 & 54 & 3.563 & 0.8932 & 161.51 & 154.02 \\
YS3 & 108 & 77 & 4.151 & 0.9557 & 171.64 & 321.31 \\
YS4 & 115 & 65 & 3.869 & 0.9269 & 159.91 & 209.37 \\
YS5 & 121 & 59 & 3.741 & 0.9275 & 106.86 & 142.94 \\
YS6 & 149 & 66 & 3.771 & 0.9001 & 466.81 & 200.04 \\
YS7 & 149 & 107 & 4.459 & 0.9543 & 373.64 & 579.72 \\
YS8 & 129 & 62 & 3.834 & 0.9290 & 126.77 & 131.93 \\
YS9 & 204 & 138 & 4.713 & 0.9565 & 498.87 & 548.14 \\
YS10 & 113 & 51 & 3.495 & 0.8889 & 80.75 & 126.56
\end{tabular}

explained $71.8 \%$ of the Actinobacteria community variation. Concentrations of MP, MT, TN, AP, and ME were strongly associated with Axis 1 (loadings of $-0.66,-0.63,0.63,0.58$, and 0.56 , respectively). $\mathrm{MT}, \mathrm{MP}, \mathrm{ME}$, and $\mathrm{TP}$ were also strongly associated with Axis $2(-0.59,-0.53,0.47$, and -0.40 respectively), and the $\mathrm{pH}(0.29,-0.15), \mathrm{OM}(0.25,0.25)$, and AK $(0.26,-0.22)$ content had lower loadings than the other factors on both axes. AAC, MP, MT, and TP were correlated with YS1, YS3, YS4, and YS5 samples. OM, AP, TN, SD, and ME were correlated with YS2, YS7, YS8, YS9, and YS10 samples. An RDA analysis was employed to determine the influence of environmental factors on the Actinobacteria community (Figure 9). The first and second dimensions explained $42.2 \%$ of the total variance. The RDA analysis revealed that the Actinobacteria community compositions were related to multiple environmental factors, and other factors that were not studied in this paper.

\section{DISCUSSION}

Actinobacteria is one of the major phyla within the domain Bacteria. Because of the high diversity of members in this phylum, it is very difficult to develop a primer system that amplifies full-length, 16S rRNA gene sequences from all Actinobacteria. In spite of this, in the present study, it was possible to adopt indirect methods so that a larger number of full sequences could be screened from the bacterial 16S rDNA clone libraries. To simplify the screening process, we used 4 primers

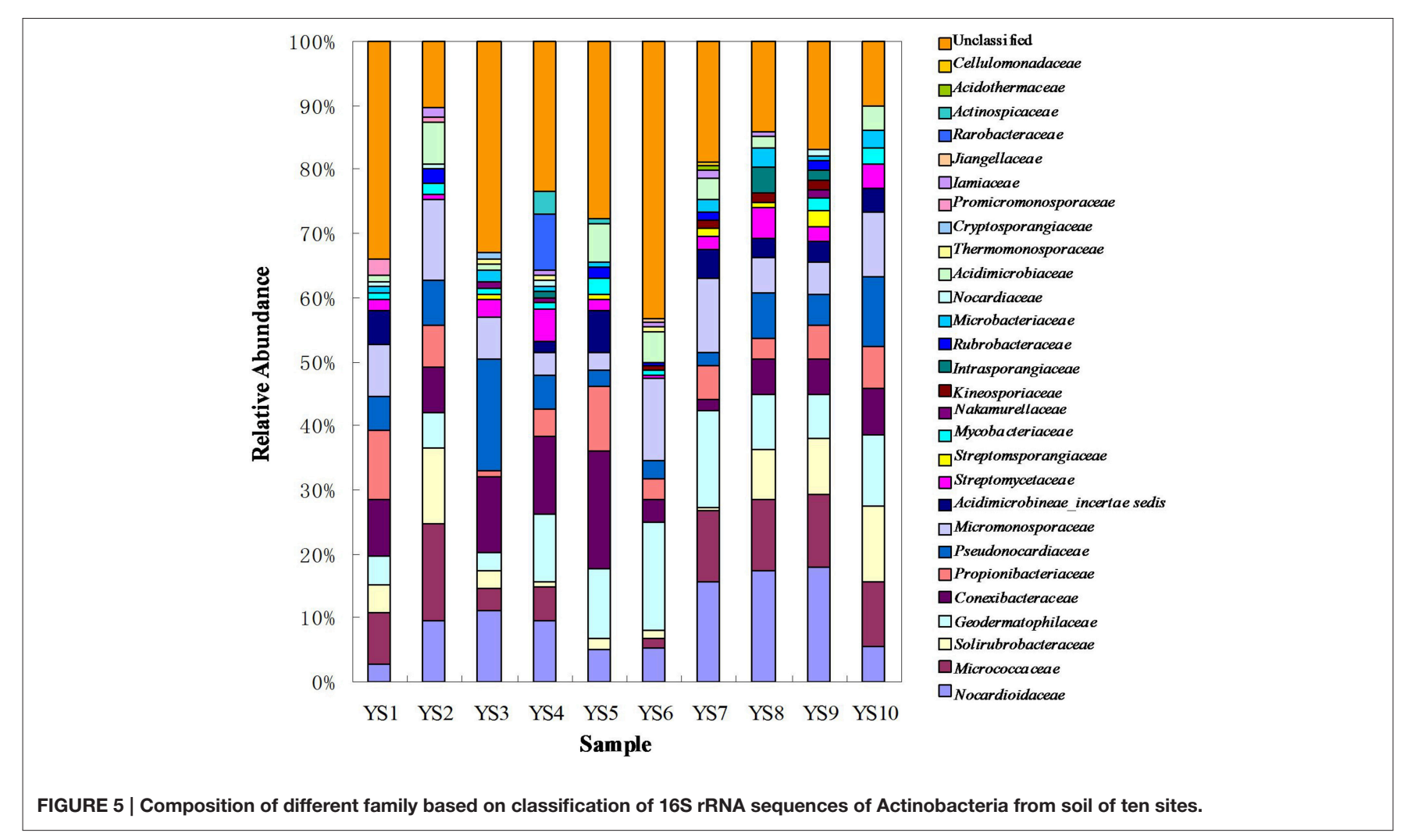




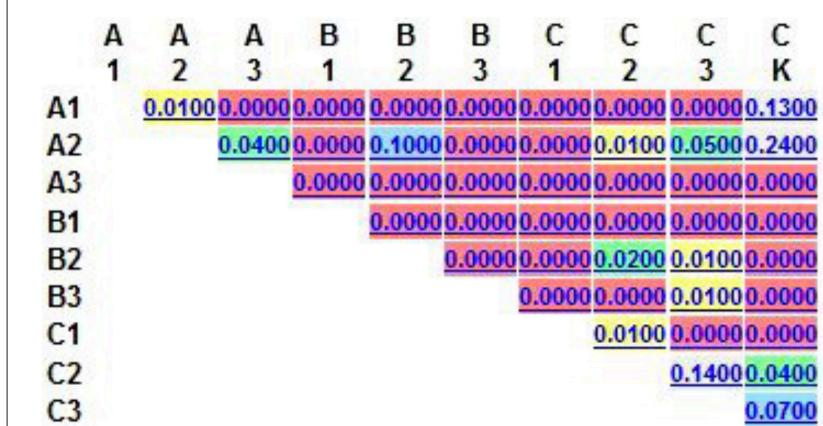

\section{Color Description}

$(<0.001)$ Highly significant

(0.001-0.01) Signific ant

(0.01-0.05) Marginally significant

(0.05-0.1) Suggestive

$(>0.1)$ Not significant

FIGURE 6 | The UniFrac significance were calculated by way of each pair of pretreatmental procotol, which tests whether each pair of environments differs from one another. Air dried soil sample were treated

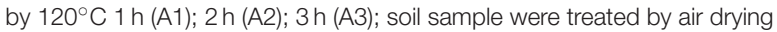
processing 15 days (B1); 30 days (B2); 45 days (B3), soil sample were treated by $0.1 \%$ Polymyxin B Sulfate immersion $1 \mathrm{~h} \mathrm{(C1);} 2 \mathrm{~h} \mathrm{(C2);} 3 \mathrm{~h}$ (C3).

at the same time, and selected clones showed amplification bands ( $\sim 270$ and/or $\sim 640 \mathrm{bp}$ ) for sequencing. Sequencing of the clone libraries clearly indicated that Actinobacteria DNA was primarily detected, with a false positive rate of $2.5 \%$. The primer systems, Com2xf/Ac1186r/SC-Act235-aS-20/SC-Act878aA-19, were suitable to screen for Actinobacteria in the $16 \mathrm{~S}$ rDNA clone libraries.

One of the aims of this study was to improve methods for detection and identification of Actinobacteria represented in 16S rDNA clone libraries derived from environmental samples. In the soil, the majority of bacterial $16 \mathrm{~S}$ rDNA products were from non-Actinobacterial strains; Actinobacteria from the $16 \mathrm{~S}$ rDNA clone library were relatively rare. In this study, we studied the effect of air-drying, heating, or $0.1 \%$ Polymyxin B Sulfate on analysis of Actinobacteria diversity using cultureindependent methods. These pre-treatment methods for the culture and isolation of Actinobacteria have been suggested by several researchers (Demain and Davies, 1999; Seong et al., 2001; Jiang et al., 2010; Jensen et al., 2015; Sun et al., 2015). Employing pretreatments of soil by drying and heating has been shown to increase the number of actinomycetes that were isolated. In this study, when the total DNA of untreated soils was extracted, the colonies recovered was mainly from other orders of bacteria (Table 1). However, no matter which pretreatment method was applied, pretreatment significantly increased the numbers of Actinobacterial colonies $(P<0.01)$, while drastically
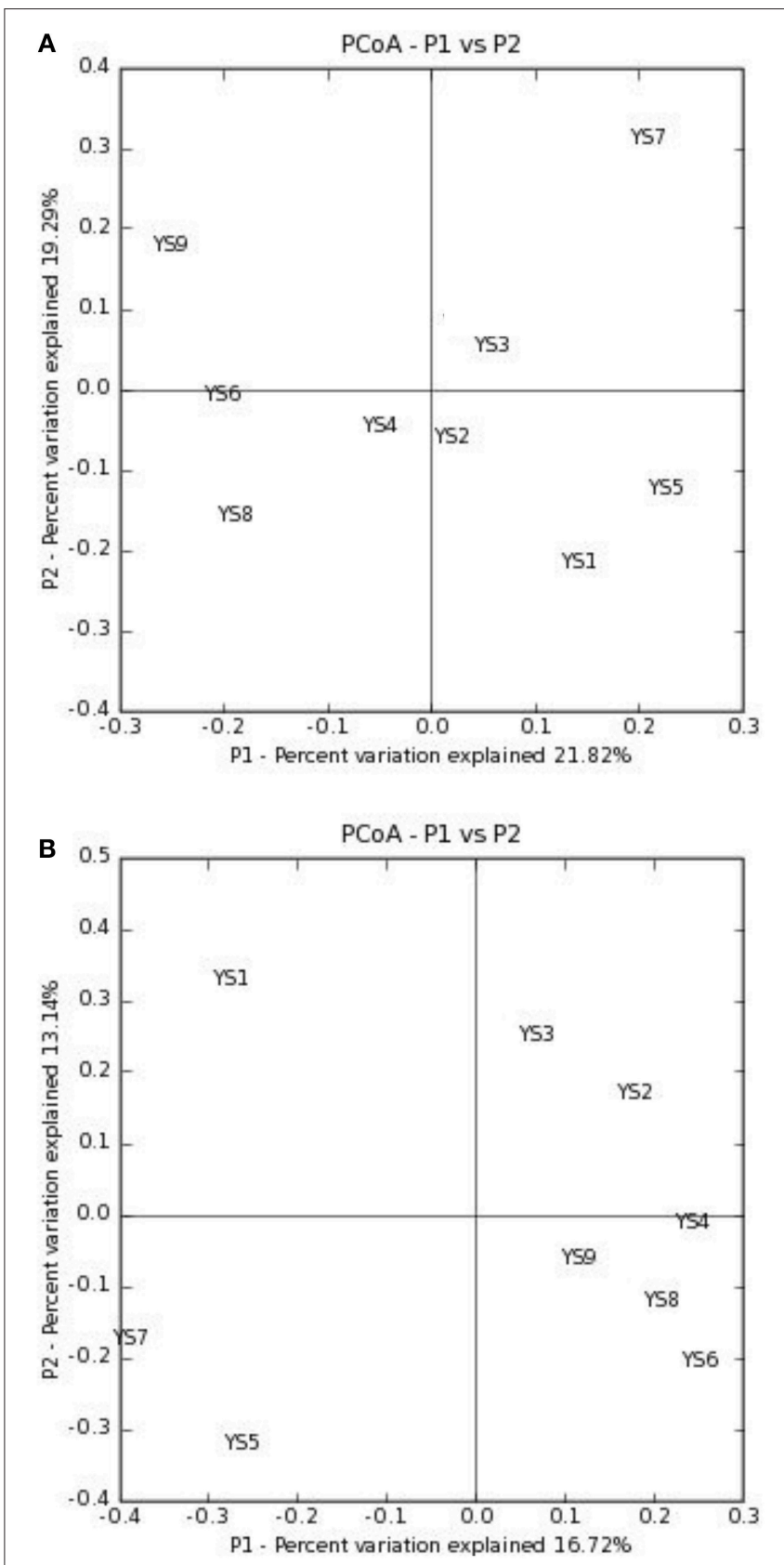

FIGURE 7 | PCoA plots are presented of the first two axes based on (A) weighted and $(B)$ unweighted Unifrac distance matrices showing the quantitative and qualitative clustering of samples.

reducing the numbers of other bacterial colonies $(P<0.01)$. The rarefaction analysis of OTUs at the 97\% level suggested that the number of clones screened (500) was insufficient to cover the diversity of Actinobacteria and the data were rarefied (Figure 2). Therefore, in our analysis of Actinobacteria diversity in the Yanshan Mountains, we increased the number of clones screened to 1000. Data confirmed that the pretreatment of soil led to an increase in the detection of Actinobacteria taxa and access to a more genetically diverse community of Actinobacteria. 
At the same time, we found that each of the soil pretreatments could not only increase the detection rate of Actinobacteria, but showed a bias toward the detection of some groups of

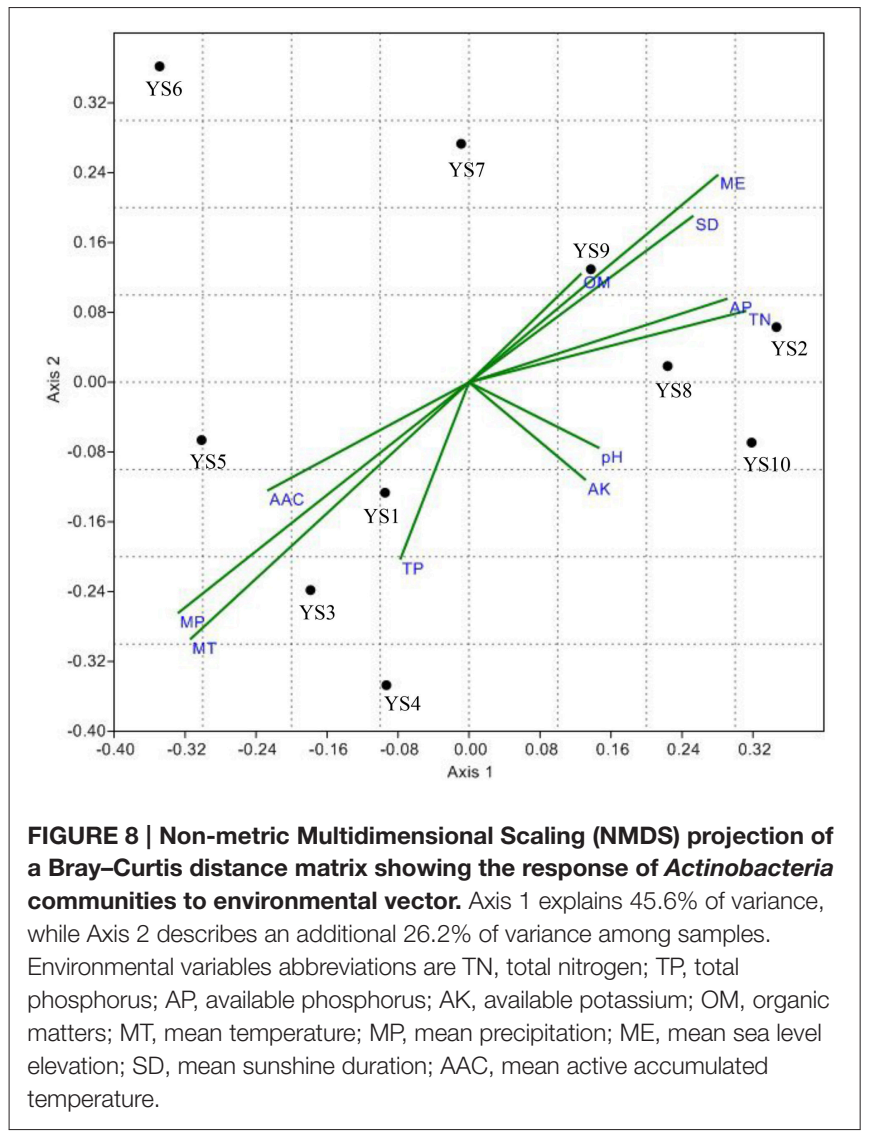

Actinobacteria. It provides a reference for the separation of the corresponding groups of Actinobacteria. Each of these treatment methods has both positive and negative aspects, in terms of their efficiency and ability to yield DNA extracts that truly represent the natural microbial community. Altogether, our results indicate that the Actinobacterial abundance and diversity that was detected might be affected by pretreatment procedures used to recover soil metagenomic DNA. Understanding these biases has become critical with the expansion of $16 \mathrm{~S}$ rDNA technologies, which allow a more comprehensive investigation of specific microbial diversity. Our study confirms the pivotal importance of soil sample pretreatment in the DNA extraction procedure. It also emphasizes the need for thorough technical surveys to increase species richness per sequencing effort to be useful in microbial diversity studies. Consequently, we need to revisit our choice of pretreatment protocols to ensure that the DNA recovered from soil is not only of good quality, but also sufficiently representative in terms of richness and evenness of the Actinobacterial populations. In contrast to untreated soils, where Actinobacteria are believed to represent only about $3.6 \%$ of the total bacterial community, investigations of pretreated soils revealed that Actinobacterial 16S rRNA genes accounted for between 4.8 and $20.4 \%$ of the total community. The detected Actinobacteria were highly diverse (A1). Compared with other pretreatment methods, Actinobacteria diversity from methods A1 and A2 were not different with $\mathrm{CK}$, as determined by the UniFrac significance test $(0.13$ and 0.24 , respectively; Figure 6). Moreover, A1 yielded 102 clones with a detection rate of $20.4 \%$, which was much higher than those found with the other pretreatment processes. Therefore, in order to gain accurate and representative phylogenetic information on Actinobacteria in the Yanshan Mountains, we chose the A1 soil pretreatment method: air drying of the soil sample, followed by

TABLE 3 | Abundance and diversity of main family from Actinobacteria.

\begin{tabular}{|c|c|c|c|c|c|c|c|c|c|c|c|c|c|c|c|c|c|c|c|c|}
\hline & \multicolumn{2}{|c|}{ YS1 } & \multicolumn{2}{|c|}{ YS2 } & \multicolumn{2}{|c|}{ YS3 } & \multicolumn{2}{|c|}{ YS4 } & \multicolumn{2}{|c|}{ YS5 } & \multicolumn{2}{|c|}{ YS6 } & \multicolumn{2}{|c|}{ YS7 } & \multicolumn{2}{|c|}{ YS8 } & \multicolumn{2}{|c|}{ YS9 } & \multicolumn{2}{|c|}{ YS10 } \\
\hline & $\mathbf{R A}^{\mathrm{a}}$ & $S I^{b}$ & RA & SI & RA & SI & RA & SI & RA & SI & RA & SI & RA & SI & RA & SI & RA & SI & RA & SI \\
\hline Nocardioidaceae & 2.1 & 1.39 & 8.5 & 1.77 & 8.5 & 1.91 & 7.8 & 1.91 & 4.2 & 1.33 & 5.7 & 1.56 & 4.3 & 2.20 & 17.0 & 2.82 & 15.6 & 1.91 & 26.2 & 3.02 \\
\hline Micromonosporaceae & 8.7 & 1.58 & 15.4 & 1.06 & 6.7 & 1.95 & 3.8 & 1.39 & 2.9 & 1.10 & 18.3 & 1.77 & 10.6 & 1.70 & 17.3 & 2.51 & 6.7 & 1.55 & 9.6 & 2.39 \\
\hline Conexibacteraceae & 9.7 & 1.75 & 8.7 & 1.87 & 12.6 & 2.49 & 13.6 & 1.58 & 21.4 & 1.64 & 4.9 & 1.73 & 7.8 & 1.61 & 2.9 & 0.69 & 6.8 & 0.00 & 11.7 & 2.06 \\
\hline Pseudonocardiaceae & 7.4 & 1.79 & 11.1 & 0.00 & 23.5 & 1.32 & 7.4 & 1.56 & 3.7 & 1.10 & 4.9 & 1.10 & 14.8 & 0.50 & 3.7 & 1.10 & 11.1 & 1.58 & 12.4 & 2.04 \\
\hline Propionibacteriaceae & 16.4 & 1.10 & 11.0 & 0.74 & 1.4 & 0.00 & 6.8 & 1.33 & 16.4 & 0.72 & 6.8 & 0.60 & 9.6 & 0.50 & 11.0 & 1.39 & 5.5 & 0.00 & 15.1 & 2.03 \\
\hline $\begin{array}{l}\text { Acidimicrobineae_incertae_ } \\
\text { sedis }\end{array}$ & 15.8 & 1.79 & 0.0 & 0.00 & 0.0 & 0.00 & 5.3 & 0.69 & 21.1 & 0.41 & 0.0 & 0.69 & 10.5 & 0.00 & 18.4 & 1.33 & 10.5 & 0.00 & 18.4 & 1.75 \\
\hline Micrococcaceae & 8.5 & 1.00 & 17.9 & 0.69 & 3.8 & 1.39 & 5.7 & 0.87 & 0.0 & 0.00 & 1.9 & 0.38 & 10.4 & 0.64 & 16.0 & 1.66 & 13.2 & 0.69 & 22.6 & 1.71 \\
\hline Geodermatophilaceae & 4.0 & 0.50 & 5.6 & 0.41 & 2.4 & 1.10 & 9.6 & 0.84 & 10.4 & 0.91 & 20.0 & 0.43 & 9.6 & 1.44 & 18.4 & 1.62 & 8.8 & 1.30 & 11.2 & 1.43 \\
\hline Streptomycetaceae & 6.1 & 0.69 & 3.0 & 0.00 & 9.1 & 0.64 & 18.2 & 0.87 & 6.1 & 0.69 & 3.0 & 0.64 & 12.1 & 0.69 & 9.1 & 0.00 & 18.2 & 0.69 & 15.2 & 1.39 \\
\hline Solirubrobacteraceae & 7.1 & 1.61 & 21.4 & 0.41 & 4.3 & 0.00 & 1.4 & 0.00 & 2.9 & 0.69 & 2.9 & 0.69 & 18.6 & 0.69 & 1.4 & 0.00 & 14.3 & 1.23 & 25.7 & 1.21 \\
\hline Streptosporangiaceae & 0.0 & 0.00 & 0.0 & 0.00 & 10.0 & 0.00 & 0.0 & 0.00 & 10.0 & 0.00 & 0.0 & 0.00 & 0. & 0.00 & 20.0 & 0.69 & 10.0 & 0.00 & 50.0 & 0.95 \\
\hline Mycobacteriaceae & 6.2 & 0.00 & 12.5 & 0.64 & 6.3 & 0.00 & 6.3 & 0.00 & 18.7 & 0.64 & 6.2 & 0.64 & 18.8 & 0.69 & 0.0 & 0.64 & 0.0 & 0.00 & 25.0 & 0.56 \\
\hline Acidimicrobiaceae & 2.9 & 0.00 & 22.8 & 0.74 & 2.9 & 0.00 & 0.0 & 0.00 & 20.0 & 0.41 & 20.0 & 1.04 & 11.4 & 0.41 & 14.3 & 1.61 & 5.7 & 0.69 & 0.0 & 0.00 \\
\hline unclassdified & 12.5 & 3.05 & 4.3 & 2.51 & 11.8 & 3.14 & 8.9 & 2.65 & 10.9 & 2.91 & 21.0 & 1.85 & 3.6 & 2.54 & 9.6 & 3.15 & 5.9 & 2.29 & 11.5 & 3.26 \\
\hline
\end{tabular}

${ }^{a}$ Relative abundance (\%) of taxonomic group with respect to total OTUs observed for community.

bShannon diversity index. 


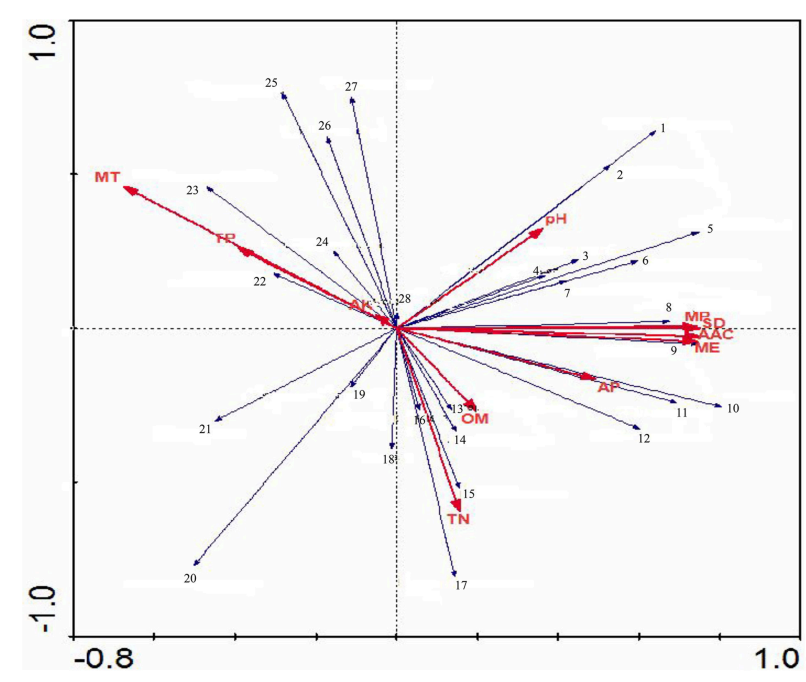

FIGURE 9 | The RDA ordination plot for the relationship between the family patterns of Actinobacteria community Clusters and environmental factors in the Yanshan mountains zone. Correlations between pattern or environmentasl factors and RDA axes are represented by the length and angle of arrows.

exposure to $120^{\circ} \mathrm{C}$ for $1 \mathrm{~h}$. With this method, we observed high Actinobacterial diversity in a relatively small number of clone libraries.

Yanshan Mountains is a famous mountain range in north China, located at N $39^{\circ} 40^{\prime} \sim 42^{\circ} 10^{\prime}$, E $115^{\circ} 45^{\prime} \sim 119^{\circ} 50^{\prime}$ in the Inner Mongolia platform anteclise and subsidence zone. The eastern slope of the mountains has low mountains and hills, and lush vegetation, including shrubs, weeds, and a vast forest area. The western slope has low and medium mountains and sparse vegetation, including shrubs and grass. The Yanshan Mountains lie in an ecologically sensitive zone of north China near the $\mathrm{Hu}$ Huanyong Line ( $\mathrm{Hu}, 1985)$. It is an ecosystem that has been adversely affected by forces of nature resulting in the destabilization of the balance of the living and nonliving organisms in it and making it vulnerable to destruction. The ecosystem is facing changes due to climate change and destructive human activity, such as the mass cutting of trees. Living organisms interact with one another in an ecosystem in a cyclic manner; therefore, when one organism is destroyed, it affects the remaining organisms (Montoya et al., 2006).

Using a 16S rRNA gene clone library as a culture-independent method to survey the Actinobacterial community of Yanshan Mountains, we found that the overall diversity observed at the different stations was very high. The high number of novel Actinobacteria detected in the environmental samples is also significant. The Antibiotic Literature Database indicates that $57.8 \%$ of the known bioactive microbial products are produced by members of the class Actinobacteria. In this study, based on a comparison of signature nucleotides with higher taxa described by Zhi et al. (2009). we identified a total of 23 unclassified Actinobacteria, representing 2 novel orders, 10 novel suborders, and 39 novel families from Yanshan Mountains. It is reasonable to conclude that these new lineages may produce novel bioactive compounds, similar to other Actinobacteria. Clearly, the diversity of Actinobacteria greatly exceeds that predicted based on culture-based estimates, and this highlights the great biotechnological value in continuing efforts to isolate novel Actinobacteria genera. The genera Conexibacter, Solirubrobacter, Microlunatus, Blastococcus, and Streptomyces were common to all stations surveyed in this study. These groups are conserved in the Yanshan Mountains. Despite changing ecologies in the different stations, they were always present. Although members of the order Solirubrobacterales have not been extensively studied, recent studies have shown their ability to adapt and colonize different ecosystems, including fungal growing ant colonies (Ishak et al., 2011), spinach phyllosphere (Lopez-Velasco et al., 2011), desert, and Antarctic soil (Chong et al., 2012). Members of the genus Blastococcus were recovered from different latitudes and climates in dry and/or extreme conditions (Salazar et al., 2006), these microorganisms have the potential to colonize and alter stone and monument surfaces. Microlunatus spp. have been isolated from marine sediments (Yuan et al., 2014), a soil sample collected from Alu, an ancient cave (Cheng et al., 2013), and from conventional farming (Li et al., 2012). Some Microlunatus spp. have phosphorusaccumulating functions and phosphate uptake/release activities (Akar et al., 2005) in the enhanced biological phosphate removal (EBPR) process, and they are believed to play a pivotal role in phosphorus removal. The EBPR process is attracting interest for its potential use in phosphorus recycling (Hirota et al., 2010). In this study, some groups seemed to be more adaptive, based on their ability to survive in various environments. In contrast, there were unique genera identified in specific site: YS1, Longispora, Propionibacterium, and Xylanimonas; YS2, Nocardia; YS3, Actinaurispora, Actinomadura, Actinomycetospora, Cryptosporangium, Humicoccus, and Phytohabitans; YS4, Actinocorallia, Actinospica, Hamadaea, Millisia, and Phycicoccus; YS5, Actinokineospora; YS6, Jiangella; YS7, Cellulomonas and Okibacterium; YS8, Rothia, Saccharothrix, and Terrabacter; YS9, Amycolatopsis, Cryobacterium, Knoellia, Nakamurella, and Rhodococcus. Endemic taxa of these different stations reflect the Actinobacterial response to different environments.

The UniFrac analysis of the stations showed that the Actinobacterial compositions of YS2, YS3, YS4, YS6, YS8, YS9, and YS10 did not differ $(P>0.1)$. It is indeed "everything is everywhere, but the environment selects," with no evident dispersal limitations on Actinobacteria, This theory suggests that each ecologically equivalent study site will have similar Actinobacterial communities due to near identical environmental variables, which eliminate environmental filtering as well as constant additions by the regional species pool. Conversely, Bissett et al. (2010) described a hypothesis of "wherever you go, that's where you are" implying that beyond strong environmental selection, other factors (i.e., dispersal or colonization limitations and evolutionary events) play a significant role in shaping microbial communities. Between YS7 and most other sites, there were significant different in Actinobacterial community composition, with YS4 and YS8 showing highly significant differences $(P<0.001)$. It has been suggested that microbial biogeographical patterns are shaped by 
environmental factors (Fierer, 2008). For instance, pH (Fierer and Jackson, 2006), temperature (Yergeau et al., 2007), and precipitation (Clark et al., 2009) have been found to be the best predictors of continent-scale patterns. It is also believed to be globally distributed by prevailing winds and community patterns are thought to result from barriers to dispersal, physiological requirements, resource availability, competition, or some combination thereof. However, Actinobacteria do not display a cosmopolitan distribution: their communities remain distinct not only over large geographical distances (Wawrik et al., 2007; Eisenlord et al., 2012) and seasonal differences (Cho et al., 2008), but also vary with local environmental factors ${ }^{54}$ and within a single sampling location (Abdulla and El-Shatoury, 2007; Van der Gucht et al., 2007). This work provides evidence that soil Actinobacterial communities exhibit regional biogeographic patterns, wherein community membership changes across the north-south distribution of $\mathrm{Hu}$ Huanyong Line. Stations YS1, YS3, YS4, and YS5 are located at the edge of the ecologically sensitive zone, the southern Yanshan Mountains, in the rain belt, and these sites are affected by the continental climate significantly. The climatic characteristics of AAC, MP, and MT and biogeochemical data of TP likely contributed to Actinobacterial communities at these stations. The ecological environments of other stations were not stable and fragile. It was clear that biogeochemical factors contributed more to

\section{REFERENCES}

Abdulla, H. M., and El-Shatoury, S. A. (2007). Actinomycetes in rice straw decomposition. Waste Manage. 27, 850-853. doi: 10.1016/j.wasman.2006.06.006

Akar, A., Akkaya, E. U., Yesiladali, S. K., Elikyilmaz, G., Okgor, E. U., Tamerler, C., et al. (2005). Accumulation of polyhydroxyalkanoates by Microlunatus phosphovorus under various growth conditions. J. Ind. Microbiol. Biot. 33, 215-220. doi: 10.1007/s10295-004-0201-2

Baas, L. G. M. (1934). Geobiologie of Inleiding tot de Milieukunde. Hague: W. P. Van Stockum \& Zoon.

Barka, E. A., Vatsa, P., Sanchez, L., Gaveau-Vaillant, N., Jacquard, C., Klenk, H. P., et al. (2016). Taxonomy, physiology, and natural products of actinobacteria. Microbiol. Mol. Biol. Rev. 80, 1-43. doi: 10.1128/MMBR.00019-15

Bissett, A., Richardson, E., Baker, G., Wakelin, S., and Thrall, P. H. (2010). Life history determines biogeographical patterns of soil bacterial communities over multiple spatial scales. Mol. Ecol. 69, 134-157. doi: 10.1111/j.1365294x.2010.04804.x

Cheng, J., Chen, W., Huo-Zhang, B., Nimaichand, S., Zhou, E. M., Lu, X. H., et al. (2013). Microlunatus cavernae sp. nov., a novel actinobacterium isolated from Alu ancient cave, Yunnan, South-West China. Antonie Van Leeuwenhoek. 104, 95-101. doi: 10.1007/s10482-013-9929-x

Chong, C. W., Convey, P., Pearce, D. A., and Tan, I. K. P. (2012). Assessment of soil bacterial communities on Alexander Island (in the maritime and continental Antarctic transitional zone. Polar Biol. 35, 387-399. doi: 10.1007/s00300-0111084-0

Cho, S. T., Tsai, S. H., Ravindran, A., Selvam, A., and Yang, S. S. (2008). Seasonal variation of microbial populations and biomass in Tatachia grassland soils of Taiwan. Environ. Geochem. Health. 30, 255-272. doi: 10.1007/s10653-0079113-1

Clark, J., Campbell, J., Grizzle, H., Acosta-Martinez, V., and Zak, J. (2009). Soil microbial community response to drought and precipitation variability in the Chihuahuan Desert. Microb. Ecol. 57, 248-260. doi: 10.1007/s00248-0089475-7
Actinobacterial community structure than chemical factors. The stability of Actinobacterial communities in different ecological environments was largely correlated with biogeochemical factors and less with climate factors, such as Streptomycelaceae and $\mathrm{pH}$, Solirubrobacteraceae and AP, Propionibacteriaceae and OM, Geodermatophilaceae and TN.

\section{AUTHOR CONTRIBUTIONS}

HT, implementation of the experiment. XS, English check. XW, English check. HH, English check. XZ, sampling. LZ, designing experimental program.

\section{ACKNOWLEDGMENTS}

The work was supported by the National Natural Science Foundation of China (No. 30970010) and Bioengineering key discipline of Hebei Province.

\section{SUPPLEMENTARY MATERIAL}

The Supplementary Material for this article can be found online at: http://journal.frontiersin.org/article/10.3389/fmicb. 2016.00343
Delmont, T. O., Robe, P., Cecillon, S., Clark, I. M., Constancias, F., Simonet, P., et al. (2010). Accessing the soil metagenome for studies of microbial diversity. Appl. Environ. Microbiol. 77, 1315-1324. doi: 10.1128/AEM.01526-10

Demain, A. L., and Davies, J. E. (1999). Manual of Industrial Microbiology and Biotechnology, 2nd Edn. Washington, DC: American Society for Microbiology Press.

Eisenlord, S. D., Zak, D. R., and Upchurch, R. A. (2012). Dispersal limitation and the assembly of soil Actinobacteria communities in a long-term chronosequence. Ecol. Evol. 2, 538-549. doi: 10.1002/ece3.210

Fierer, N., and Jackson, R. B. (2006). The diversity and biogeography of soil bacterial communities. Proc. Natl. Acad. Sci. U.S.A. 103, 626-631. doi: 10.1073/pnas.0507535103

Fierer, N. (2008). "Microbial biogeography: patterns in the microbial diversity across space and time," in Accessing Uncultivated Microorganisms: from the Environment to Organisms and Genomes and Back, ed K. Zengler (Washington, DC: ASM Press), 95-115.

Green, J. L., Bohannan, B. J., and Whitaker, R. J. (2008). Microbial biogeography: from taxonomy to traits. Science 320, 1039-1043. doi: 10.1126/science.1153475

Han, P. P., Shen, S. G., Jia, S. R., Wang, H. Y., Zhong, C., Tan, Z. L., et al. (2015). Comparison of bacterial community structures of terrestrial cyanobacterium Nostoc flagelliforme in three different regions of China using PCR-DGGE analysis. World J. Microbiol. Biotechnol. 31, 1061-1069. doi: 10.1007/s11274015-1856-8

Hirota, R., Kuroda, A., Kato, J., and Ohtake, H. (2010). Bacterial phosphate metabolism and its application to phosphorus recovery and industrial bioprocesses. J. Biosci. Bioeng. 109, 423-432. doi: 10.1016/j.jbiosc.2009.10.018

Hu, H. Y. (1985). Distribution of the Population of China. Shanghai: East China Normal University Press.

Ishak, H. D., Miller, J. L., Sen, R., Dowd, S. E., Meyer, E., and Mueller, U. G. (2011). Microbiomes of ant castes implicate new microbial roles in the fungusgrowing ant Trachymyrmex septentrionalis. Sci. Rep. 1:204. doi: 10.1038/srep 00204

Janelle, R. T., Marcelino, L. A., and Polz, M. F. (2002). Heteroduplexes in mixed-template amplifications: formation, consequence and elimination 
by reconditioning PCR. Nucleic Acids Res. 30, 2083-2088. doi: 10.1093/nar/30.9.2083

Jensen, P. R., Moore, B. S., and Fenical, W. (2015). The marine actinomycete genus Salinispora: a model organism for secondary metabolite discovery. Nat. Prod. Rep. 32, 738-751. doi: 10.1039/C4NP00167B

Jiang, Y., Cao, Y., Zhao, L., Wang, Q., Jin, R., He, W., et al. (2010). Ultrasonic treatment of soil samples for actinomycete isolation. Wei Sheng Wu Xue Bao. 50, 1094-1097.

Kemp, P. F., and Aller, J. Y., (2004). Estimating prokaryotic diversity: when are 16S rDNA libraries large enough? Limnol. Oceanogr. 2, 114-125. doi: 10.4319/lom.2004.2.114

Kuang, W., Li, J., Zhang, S., and Long, L. (2015). Diversity and distribution of Actinobacteria associated with reef coral Porites lutea. Front. Microbiol. 6:1094 doi: 10.3389/fmicb.2015.01094

Lane, D. J. (1991). "16S/23S rRNA sequencing" in Nucleic Acid Techniques in Bacterial Systematics, eds E. Stackebrandt and M. Goodfellow (Chichester: Wiley), 115-175.

Lazzaro, A., Hilfiker, D., and Zeyer, J. (2015). Structures of microbial communities in alpine soils: seasonal and elevational effects. Front. Microbiol. 6:1330 doi: 10.3389/fmicb. 2015.01330

Li, R., Khafipour, E., Krause, D. O., Entz, M. H., de Kievit, T. R., and Fernando, W. G. (2012). Pyrosequencing reveals the influence of organic and conventional farming systems on bacterial communities. PLoS ONE 7:e51897. doi: 10.1371/journal.pone.0051897

Logares, R., Sunagawa, S., Salazar, G., Cornejo-Castillo, F. M., Ferrera, I., Sarmento, $\mathrm{H}$, et al. (2014). Metagenomic $16 \mathrm{~S}$ rDNA Illumina tags are a powerful alternative to amplicon sequencing to explore diversity and structure of microbial communities. Environ. Microbiol. 16, 2659-2671 doi: 10.1111/14622920.12250

Lozupone, C., Hamady, M., and Knight, R. (2006). UniFrac: an online tool for comparing microbial community diversity in a phylogenetic context. BMC Bioinformatics. 7:371. doi: 10.1186/1471-2105-7-371

Lopez-Velasco, G., Welbaum, G. E., Boyer, R. R., Mane, S. P., and Ponder, M. A. (2011). Changes in spinach phylloepiphytic bacteria communities following minimal processing and refrigerated storage described using pyrosequencing of 16S rRNA amplicons. J. Appl. Microbiol. 110, 1203-1214. doi: 10.1111/j.13652672.2011.04969.x

Ventura, M., Canchaya, C., Tauch, A., Chandra, G., Fitzgerald, F. G., Chater, K. F., et al. (2007). Genomics of Actinobacteria: tracing the evolutionary history of an ancient phylum. Microbiol. Mol. Biol. Rev. 71, 495-548. doi: 10.1128/MMBR.00005-07

Mendes, L. W., Tsai, S. M., Navarrete, A. A., and Hollander, M. (2015). Soil-borne microbiome: linking diversity to function. Microbial. Ecol. 70, 255-265 doi: 10.1007/s00248-014-0559-2

Montoya, J. M., Pimm, S. L., and Solé, R. V. (2006). Ecological networks and their fragility. Nature 442, 259-264. doi: 10.1038/nature04927

Mullowney, M. W., Hwang, C. H., Newsome, A. G., Wei, X., Tanouye, U., Wan, B., et al. (2015). Diazaanthracene antibiotics from a freshwater-derived actinomycete with selective antibacterial activity toward Mycobacterium tuberculosis. ACS Infect Dis. 1, 168-174. doi: 10.1021/acsinfecdis. 5 b00005

Oksanen, J., Blanchet, G., Kindt, R., Legendre, P., O’Hara, R. B., Simpson, G. L., et al. (2011). Vegan: Community Ecology Package. R package version 1.17-11. Available online at: http://CRAN.R-project.org/package=vegan

Pace, N. R., Stahl, D. J., Lane, D. J., and Olsen, G. J. (1985). Analyzing natural microbial populations by rRNA sequences. ASM News 51, 4-12.

Poitelon, J. B., Joyeux, M., Welté, B., and Duguet, J. P., Prestel, E., Lespinet, O., et al. (2009). Assessment of phylogenetic diversity of bacterial microflora in drinking water using serial analysis of ribosomal sequence tags. Water Res. 43, 4197-4206. doi: 10.1016/j.watres.2009.07.020

Ramette, A., and Tiedje, J. M. (2007). Biogeography: an emerging cornerstone for understanding prokaryotic diversity, ecology, and evolution. Microb. Ecol. 53, 197-207. doi: 10.1007/s00248-005-5010-2

Robe, P., Nalin, R., Capellano, C., Vogel, T. M., and Simonet, P. (2003). Extraction of DNA from soil.Eur. J. Soil Biol. 39, 183-190. doi: 10.1016/S11645563(03)00033-5

Salazar, O., Valverde, A., and Genilloud, O. (2006). Real-time PCR for the detection and quantification of geodermatophilaceae from stone samples and identification of new members of the genus blastococcus. Appl. Environ. Microbiol. 72, 346-352. doi: 10.1128/AEM.72.1.346-352.2006

Schäfer, J., Jäckel, U., and Kämpfer, P. (2010). Development of a new PCR primer system for selective amplification of Actinobacteria. FEMS Microbiol Lett. 311, 103-112. doi: 10.1111/j.1574-6968.2010.02069.x

Schloss, P. D., and Handelsman, J. (2005). Introducing DOTUR, a computer program for defining operational taxonomic units and estimating species richness. Appl. Environ. Microbiol. 71, 1501-1506. doi: 10.1128/AEM.71.3.1501-1506.2005

Seong, C. H., Choi, J. H., and Baik, K. S. (2001). An improved selective isolation of rare actinomycetes from forest soil. J. Microbiol. 17, 23-39.

Sogin, M. L., Morrison, H. G., Huber, J. A., Mark, W. D., Huse, S. M., Neal, P. R., et al. (2006). Microbial diversity in the deep sea and the underexplored "rare biosphere." Proc. Natl. Acad. Sci. U.S.A. 103, 12115-12120. doi: 10.1073/pnas.0605127103

Stach, J. E., Maldonado, L. A., Ward, A. C., Goodfellow, M., and Bull, A. T. (2003). New primers for the class Actinobacteria: application to marine and terrestrial environments. Environ. Microbiol. 5, 828-841. doi: 10.1046/j.14622920.2003.00483.x

Sun, W., Zhang, F., He, L., Karthik, L., and Li, Z. (2015). Actinomycetes from the South China Sea sponges: isolation, diversity, and potential for aromatic polyketides discovery. Front Microbiol. 6:1048. doi: 10.3389/fmicb.2015.01048

Vasileiadis, S., Puglisi, E., Arena, M., Cappa, F., Cocconcelli, P. S., and Trevisan, M. (2012). Soil bacterial diversity screening using single $16 \mathrm{~S}$ rRNA gene $\mathrm{V}$ regions coupled with multi-million read generating sequencing technologies. PLoS ONE 7:e42671. doi: 10.1371/journal.pone.0042671

Van der Gucht, K., Cottenie, K., Muylaert, K., Vloemans, N., Cousin, S., Declerck, S., et al. (2007). The power of species sorting: local factors drive bacterial community composition over a wide range of spatial scales. Proc. Natl. Acad. Sci. U.S.A. 104, 20404-20409. doi: 10.1073/pnas.0707200104

Wawrik, B., Kutliev, D., Urinova, A. A., Kukor, J. J., Zylstra, G. J., and Kerkhof, L. (2007). Biogeography of actinomycete communities and type II polyketide synthase genes in soils collected in New Jersey and Central Asia. Appl. Environ. Microbiol. 73, 2982-2989. doi: 10.1128/AEM.02611-06

Wang, Q., Garrity, G. M., Tiedje, J. M., and Cole, J. R. (2007). Naive Bayesian classifier for rapid assignment of rRNA sequences into the new bacterial taxonomy. Appl. Environ. Microbiol. 73, 5261-5267. doi: 10.1128/AEM.000 62-07

Yang, J., Li, X., Huang, L., and Jiang, H. (2015). Actinobacterial diversity in the sediments of five cold springs on the qinghai-tibet plateau. Front. Microbiol. 6:1345 doi: $10.3389 /$ fmicb.2015.01345

Yergeau, E., Newsham, K. K., Pearce, D. A., and Kowalchuk, G. A. (2007), Patterns of bacterial diversity across a range of Antarctic terrestrial habitats. Environ. Microbiol. 9, 2670-2682. doi: 10.1111/j.1462-2920.2007.01379.x

Yim, B., Winkelmann, T., Ding, G. C., and Smalla, K. (2015). Different bacterial communities in heat and gamma irradiation treated replant disease soils revealed by $16 \mathrm{~S}$ rRNA gene analysis - contribution to improved aboveground apple plant growth? Front. Microbiol. 6:1224. doi: 10.3389/fmicb.2015.01224

Yuan, M., Yu, Y., Li, H. R., Dong, N., and Zhang, X. H. (2014). Phylogenetic diversity and biological activity of actinobacteria isolated from the Chukchi Shelf marine sediments in the Arctic Ocean. Mar Drugs 12, 1281-1297. doi: $10.3390 / \mathrm{md} 12031281$

Zhi, X. Y., Li, W. J., and Stackebrandt, E. (2009). An update of the structure and 16S rRNA gene sequence-based definition of higher ranks of the class Actinobacteria, with the proposal of two new suborders and four new families and emended descriptions of the existing higher taxa. Int. J. Syst. Evol. Microbiol. 59, 589-608. doi: 10.1099/ijs.0.65780-0

Conflict of Interest Statement: The authors declare that the research was conducted in the absence of any commercial or financial relationships that could be construed as a potential conflict of interest.

Copyright (c) 2016 Tang, Shi, Wang, Hao, Zhang and Zhang. This is an open-access article distributed under the terms of the Creative Commons Attribution License (CC $B Y)$. The use, distribution or reproduction in other forums is permitted, provided the original author(s) or licensor are credited and that the original publication in this journal is cited, in accordance with accepted academic practice. No use, distribution or reproduction is permitted which does not comply with these terms. 